\title{
BMJ Open Partly randomised, controlled study in children aged 6-10 years to investigate motor and cognitive effects of a 9-week coordination training intervention with concurrent mental tasks
}

\author{
Antonia Santner, ${ }^{1,2}$ Martin Kopp, ${ }^{1}$ Peter Federolf ${ }^{1}$
}

To cite: Santner A, Kopp M, Federolf P. Partly randomised, controlled study in children aged $6-10$ years to investigate motor and cognitive effects of a 9-week coordination training intervention with concurrent mental tasks. BMJ Open 2018;8:e21026. doi:10.1136/ bmjopen-2017-021026

- Prepublication history for this paper is available online. To view these files, please visit the journal online (http://dx.doi org/10.1136/bmjopen-2017021026).

Received 7 December 2017 Revised 9 March 2018 Accepted 19 April 2018
Check for updates

${ }^{1}$ Department of Sport Science, University of Innsbruck, Innsbruck, Austria

${ }^{2}$ Sportunion Tirol, Innsbruck, Austria

Correspondence to Antonia Santner; antonia.santner@student.uibk. ac.at

\section{ABSTRACT}

Introduction Physical training may play a prominent role in the development of preadolescent brains, but it is yet to be determined what type of exercise may generate higher cognitive effects, and if concurrent mental engagement provides further efficacy. The aim of this study is to investigate motor and cognitive effects of a 9-week exercise intervention in children aged 6-10 years. Trainings include the automatisation of challenging coordination exercises with concurrent mental tasks (intervention group) and multisport exercises with and without mental tasks (two control groups). It is hypothesised that all groups gain motor and cognitive effects, but highest benefits are expected for the combination of automatised coordination exercises with mental tasks.

Methods and analysis Two elementary schools $(\sim 500$ students) take part in the study. Data are generated by using the German Motor Performance Test 6-18 (Deutscher Motorik-Test 6-18), TDS (Match 4 Point), d2-R test of attention and Kasel-Concentration-Task for Children Aged 3-8 Years; test-duration: 6-7 min. After pretesting in September 2017 and a 9-week training intervention, post-testing takes place in December 2017 and March 2018 (long-term effects). Training interventions consist of coordination exercises with concurrent mental tasks (intervention group) and multimotor exercises with and without concurrent mental tasks (control groups). ShapiroWilk test will be used to test for normal distribution and the Levene test for variance homogeneity. The appropriate multivariate statistical methods (multivariate analysis of variance or Kruskal-Wallis test) will be used for analysing differences among the groups and for comparing preintervention with postintervention performances. Ethics and dissemination All procedures have been approved by the board for ethical questions in science of the University of Innsbruck. Findings will be published in 2018 in international journals and presented at conferences. Schools will be informed of key results.

\section{INTRODUCTION}

Expectations for children's academic attainments are rising, and school systems are
Strengths and limitations of this study

- Measuring of long-term effects 3 months after intervention phase.

- Training interventions represent school-related processes and are adapted according to performance levels.

- Classes are instructed by briefed professional trainers.

- Short intervention duration (9 weeks, one $50 \mathrm{~min}$ lesson/week/class)

- Unnoticed differences between selected schools may influence the outcome of the study as they represent the intervention group (school A) and control groups (school B)

- Inhomogeneous group sizes.

constantly under scrutiny regarding their ability to provide a stimulating environment that promotes learning and the development of cognitive as well as motor skills. Research findings suggest that physical training may play a prominent role in supporting the development of preadolescent brains. ${ }^{1-3}$ Several studies report that the chance of achieving better academic performances during childhood tends to rise with the level of physical fitness in children ${ }^{4-6}$ and vice versa, the probability of children receiving poorer school grades tends to rise when they perform low scores in fitness tests. ${ }^{7}$ Not only do analyses support evidence of positive effects of fitness levels on academic outcomes but also on a possible relationship on cognitive development. ${ }^{8-11}$ Hence, poorer fitness in children may correlate with lower cognitive abilities ${ }^{12}$ and children with better motor abilities may be associated with better cognitive performances. ${ }^{13-17}$ Howie and Pate ${ }^{10}$ reviewed 32 observational studies in children (from 2007 to 2012) examining associations between 
physical performance and academic achievements or cognitive functions. Thirty studies assessed positive relationships while only two found no correlations. Howie and Pate $^{10}$ also reviewed experimental studies between 2007 and 2012 (26 reviewed studies, 10 acute and 16 chronic training interventions; sample range 18-1820) and found that 24 physical activity-related studies reported positive outcomes on academic achievement (10 studies) or cognitive functions (14 studies); only two studies found no effects. Although correlations between exercising and cognitive developments are verifiable, incongruent results still exist. For example, Maher et $a l^{18}$ observed a positive relationship between higher academic achievements and longer sedentary time, indicating that sedentary behaviour may positively affect writing and numeracy skills.

Regarding the transfer of scientific findings into day to day life and the development of useful education suggestions, training interventions offer a great possibility to learn more about the efficacy of specific motor exercises. So far, experimental research in preadolescent children mainly concentrates on acute and chronic cardiovascular and motor coordination training interventions and their effects on cognitive abilities (eg, attention, executive functions-intuition, working memory, reaction time). Studies examining the impact of aerobic exercise bouts in children (eg, treadmill walking) show increased attention abilities ${ }^{19} 20$ but also diverging outcomes on task performance (eg, no changes in task performance ${ }^{19}$ vs improvement of task performance, ${ }^{20}$ and no effects on working memory and reaction time ${ }^{19}$ ). A meta-analysis of de Greeff $e t a l^{21}$ indicates that acute physical activity may have small to moderate impacts on attention while longer lasting physical interventions tend to offer positive effects on executive functions. For example, a chronic cardiovascular orientated intervention by Hillman et $a l^{22}$ revealed improved executive functions (inhibition control and cognitive flexibility, changes in neural indices of attention, processing speed and higher performance in executive control tasks), indicating that results may be due to dose-response benefits as the intervention group participated in 2 hours of aerobically demanding exercises and low organisational games each day for 9 weeks. A comparable study in relation to dose-response benefits revealed similar evidence of improved executive functions and mathematical performance in overweight children after regular aerobic exercising for 3 months $\left(20-40 \mathrm{~min} /\right.$ day). ${ }^{23}$ Exercise frequency and intensity may be an influencing factor although in comparison, Tarp $e t a l,{ }^{24}$ who investigated on a 20 -week multifaceted exercise intervention (60 min of physical activity during school time, 5-10 min of physical activity homework, a 2-week focus on cycling) did not observe any significant cognitive differences between intervention and control group. Diamond and $\mathrm{Ling}^{25}$ argue that outcomes on cardiovascular interventions may be due to the fact that children at higher aerobic fitness levels generally seem to have better executive functions. ${ }^{25}$ Hillman and Biggan ${ }^{9}$ also highlight that cardiorespiratory fitness appears to be linked to cognitive abilities and brain health. Statements which correspond with findings of Tsai $e t a l,{ }^{26}$ who discovered increased Brain Derived Neurotrophic Factor (BDNF) levels in higher-fit and lower-fit adults as well as responding effects (eg, reduced reaction times) after acute aerobic exercise but yet indicated that only higher-fit participants gained specific neuronal effects. Findings of brain imaging studies emphasise the evidence that physically fit children show larger hippocampal volume and perform better on relational memory tasks than less-fit children ${ }^{27}$; ; higher fit children may also be associated with faster neuroelectrical responses linked to language skills. ${ }^{29}$ Referring to Diamond and $\mathrm{Ling}^{25}$ again, they argue that aerobic exercises without cognitive challenges produce minor to no effects in children's executive functions and that largest outcomes may be delivered by interventions which include demanding cognitive tasks. De Greeff $e t a l^{21}$ support this assumption and also indicate that interventions focusing on cognitively engaging physical activity may produce larger benefits in executive functions in children. Ishihara $e t a l^{30}$ suggest that gamebased activities (tennis) may be beneficial for developing executive functions in children-underlining the findings of Pesce et al, ${ }^{31}$ who suspected cognitive engagement concurrent in team games to be responsible for higher effects in memory abilities (effects of playing team games for 1 hour compared with cardiovascular training and non-activity programmes). Schmidt $e t a l^{32}$ researched along the same topic (comparing a high cardiovascular training intervention over a time span of 6 weeks (12 lessons for $45 \mathrm{~min}$ ) with the participation in team games which afforded high cognitive efforts; only the team games intervention showed increases in executive functions: shifting performance; no effects in inhibition and updating). ${ }^{32}$ van der Niet $e t a l^{33}$ analysed the effects of a chronic aerobic training intervention with cognitively engaging exercises (22 weeks, 30 min two times per week) in children. Compared with the control group, students of the intervention group gained enhanced executive skills in inhibition and verbal working memory. ${ }^{33}$ Similar results in executive functions were found in a study in children by Crova et $a l^{34}$ who examined the effects of cognitive enhanced physical activity programmes (1-hour physical education class and two supplemental hours of skill-based tennis training for 21 weeks). Studies like these defend the assumption on the beneficial support of cognitive development in children through cognitive enhanced physical education. Hence, the question may be raised if training interventions focusing on coordination exercises could be an effective way in gaining higher cognitive performance levels. Recent research in children indicates a positive relationship between gross motor skills ${ }^{35}$ and/or fine motor skills ${ }^{35} 36$ towards executive functions in children. Geertsen $e t a p^{37}$ associated fine and gross motor skills in children with better performance in cognitive domains like reaction time, sustained attention ability, spatial working memory, the ability to 
learn paired associates and free-recall word memory. A study on effects of short bouts (10 min of training) of coordination exercises compared with standard physical education lessons showed a general enhancement of attentional performance in both groups but higher improvements after the coordination training. ${ }^{38}$ Other findings of an acute coordination training intervention (throwing and kicking balls on targets) in younger children show small to moderate correlations between executive (accuracy, reaction time) and motor functions, but failed to reach a significant level. ${ }^{39}$ However, coordination skill related to chronic training interventions in children provide evidence of improved executive function abilities (cognitive flexibility and inhibitory control) ${ }^{40}$ faster reaction times ${ }^{41-43}$ and higher response accuracy. ${ }^{43}$ Gallotta et $a t^{44}$ investigated on a 5-month training intervention (two lessons of physical activity per week) comparing coordination exercises, traditional physical education and a control group of children who did not take part in physical activity programmes. Both intervention groups improved significantly in attention ability but the group emphasising coordination training benefited the most. ${ }^{44}$ Overall, Tomporowski $e t a l^{45}$ offer a critical overview of different research approaches and summarise quantitative (acute bouts and dose-related chronic interventions of aerobic exercises) and qualitative interventions (acute and chronic exercising with increased task complexity, mental engagement and challenging variations) - they hypothesise that mentally challenging tasks may lead to procedural and declarative skill development; therefore, higher impacts in children's cognition and metacognition (problem-solving strategy development towards reaching specific goal performances) might be gained. ${ }^{45}$

In summary, several research studies in children report positive effects, not only of cardiovascular training but also of coordination training, on various cognitive functions. Latest reviews support the hypothesis that physical activity with high cognitive loads may lead to higher improvements of cognition in children. Some researchers argue that aerobic exercises without cognitive challenges produce minor to no effects in children's executive functions and that largest outcomes may be delivered by interventions which include demanding cognitive tasks. In fact, dual-task training interventions show interesting impacts on motor skills (eg, gait performance, postural stability) ${ }^{46} 47$ and executive functions ${ }^{46}$ and possible additional activation of brain networks in adults. ${ }^{48}$ However, there is much more research needed to learn about the effects of exercising with concurrent mental tasks in children. Also, training interventions with coordination tasks of diverging intensities and frequencies are necessary to deliver much-needed insight into influence opportunities on children's brain and cognitive development. Another interesting hypothesis, which-to the best of our knowledge-has not been directly examined in children so far, involves the role of automatisation of motor skills within coordination training interventions. The automatisation of complex movement tasks (eg, bimanual activities in music training) may stimulate sensorimotor integration, restructuring of neural architectures and interhemispheric efficacy ${ }^{49}$ which are all foundational processes for intellectual progression. One might therefore hypothesise that physical exercises that not only train coordinative motor skills, but specifically emphasise the automatisation of movement sequences through repetition, might also facilitate the development of specific cognitive functions. Research $^{50}{ }^{51}$ indicates that repetitive practice affects motor and/or cognitive performance positively.

The authors of the current study are particularly interested in the effects of exercise interventions on attention abilities in children, as these may generate important impacts on academic achievements. ${ }^{52}$ Selective attention implies the suppression of distracting surroundings and may be responsible for multiplying effects in learning abilities. ${ }^{53}$ Lan et a $\tilde{l}^{4}$ even claim that compared with executive functions (such as working memory and inhibitory control) attentional control can reliably predict achievements in language (eg, completing sentences, reading) and mathematical skills (eg, counting, calculating) in children. Although attention is perceived as lower-order cognitive process, Rusch et a $a{ }^{55}$ recently indicated that selective attention might be a key mechanism for dealing with complex learning problems.

The purpose of the current study is to compare effects of the 'Kort.X' training programme-a complex coordination training with concurrent mental tasks which specifically emphasises the automatisation of complex movement sequences-with a standard multiexercise programme currently educated in Austrian elementary schools. Researchers target children aged $6-10$ years and plan a chronic training intervention for 9 weeks. The main hypothesis of this study is that children gain higher attention benefits from the automatisation of challenging coordination exercises and simultaneously high engagement through mental tasks (group A) compared with standard physical education programmes without (control group B1) or with concurrent mental tasks (control group B2). It is estimated that the inclusion of mental tasks during standard school exercise programmes will gain supplementary attentional effects for control group B2, although results may not reach outcomes of the cognitive intervention group (group A). Researchers presume that coordinative skills, like reaction time, balance ability or general agility may show some group differences since the exercises in group A emphasise the automatisation of challenging coordinative tasks.

\section{METHODS AND ANALYSIS}

\section{Study design: sampling}

This partly randomised, controlled study involves two elementary schools and their approximately 500 students in the age range of 6-10 years. Both schools (school A and school B) are situated in small-town areas in Tyrol, Austria within a distance of $4 \mathrm{~km}$ and were selected specifically due to their similarities in school size, student's backgrounds, 


\begin{tabular}{llll} 
Table 1 Training intervention (groups) & & \\
\hline Groups & $\begin{array}{l}\text { Coordination } \\
\text { - automatisation }\end{array}$ & $\begin{array}{l}\text { Multimotor exercises } \\
\text { extas }\end{array}$ & $\begin{array}{l}\text { Mental } \\
\text { tasks }\end{array}$ \\
\hline $\begin{array}{l}\text { School A (13 classes) } \\
\text { Control group (B1, }\end{array}$ & $\mathrm{x}$ & $\mathrm{x}$ \\
$\begin{array}{l}\text { seven classes) } \\
\begin{array}{l}\text { Control group (B2, } \\
\text { four classes) }\end{array}\end{array}$ & $\mathrm{x}$ & $\mathrm{x}$ \\
\hline
\end{tabular}

school facilities and identical education curricula. In both schools, teachers were informed about the study aim and methods in a conference and presented with the possibility to raise questions and eventual concerns during the presentation. There was unanimous approval to take part in the study and the consent to support the execution of test design and training intervention by coordinating time tables and guiding children was given by all involved.

One school (school A, n=285, 13 classes) was selected for the coordination-automatisation-mental exercises (Kort.X programme). The other school (school B, n=216, 11 classes) was selected randomly as control groups. Specifically, two control groups were formed by drawing class numbers (by a blinded trainer) and assigning the classes into two groups: group B1 (seven classes) receives a 9-week training intervention with a multimotor exercise (MME) programme but without an emphasis on automatisation of movement sequences. Group B2 (four classes, one class of each school grade) receives the MME training and concurrently train the exact same school-related mental tasks as group A (table 1). In both schools, teachers were informed about the study aim and methods in a conference and presented with the possibility to raise questions and eventual concerns during the presentation. There was unanimous approval to take part in the study, and the consent to support the execution of test design and training intervention by coordinating time tables and guiding children was given by all involved.

\section{Training/exercise intervention}

Over a time of 10 weeks ( 9 weeks training plus 1 week autumn holidays), each school class receives a $50 \mathrm{~min}$ sports programme per week. A child must attend a minimum of eight lessons to get included in data analyses. Absences are protocolled by trainers and forwarded to researchers. To mimic school routines, interventions take place in the gym halls of the schools. Two female sport coaches, with similar education levels and years of experience of working with children age 6-10 years (sports instructor education with main emphasis on preadolescent and adolescent training programmes) were selected to educate the training programmes. All training intervention programmes (school-related mental tasks included) are predesigned and weekly adjusted to the performance levels of classes and the feedback of teachers and sport coaches. Same-grade classes within the test groups (A, B1 and B2) receive the same exercises-content, intensity and duration are the same.

\section{Intervention group (school A)}

The coordination-automatisation-mental exercises that students in group A receive are based on a standardised training programme called 'Kort.X' (www.kortx.info) which consists of challenging coordination exercises and concurrent mental tasks. Specifically, the training programme builds up in three stages: activation $(10 \mathrm{~min})$, learning $(25 \mathrm{~min})$ and automatisation $(10 \mathrm{~min})$. The first 10 min of each lesson are dominated by cardiovascular activities (playful running exercises) which aim to release excessive energy in children. During the second part of the sports programme, coaches introduce challenging coordination exercises that focus on variations in orientation, rhythm, balance, differentiation, adaptive and combination abilities. ${ }^{56}$ By using lines of coordination hoops (12-15 hoops per line), children first learn sequences of footsteps. Once these step sequences are performed fast and without mistakes, sequences of the arms are supplemented which are performed in a different rhythm than step sequences. When children have learnt to control the combination of these two different rhythms in arms and legs, the control of finger movements follow, and the exercises will progress into further tasks (eg, variations between left-sided and right-sided limbs, forward/backward/sideways movement, supplemental tasks depending on loop colours, acoustic or visual signals, partner exercises and many more). Additionally, and concurrently to performing exercises in fluent movement, students are challenged with school-related mental tasks (eg, counting backwards; multiplication tables; spelling words and answering questions about geography, biology, nature and other school-related topics which are educated at that time). After the main coordination part which lasts for approximately $25 \mathrm{~min}$, sport coaches choose two exercise variations which will be automatised at the end of the lesson. For the last $10 \mathrm{~min}$, every student receives five hoops, positions them in line and trains selected exercise variation along the following mode: exercise 1 is automatised by doing six rounds of $30 \mathrm{~s}$ training interval followed each time by a $12 \mathrm{~s}$ break. Exercise 2 is automatised along the same mode. Sport coaches give signals when to train and when to rest. After this last automatisation part, the lesson ends.

\section{Control groups (B1 and B2)}

Control group B1 (seven classes) receives a training programme with MMEs that demand cardiovascular abilities, strength, speed, flexibility and coordination skills. For warming up, children play games (catching games, ball games, running games) for about $10-15$ min. For the main part, students are challenged with a mix of exercises from different sports like gymnastics, athletics, ball games or, for example, climbing. They learn skills like sprinting, jumping, throwing, climbing, catching, targeting or falling the right way without getting hurt. Every lesson will end with games or common exercises that offer possibilities of learning and adapting social skills and fair play. The second control group (B2) receives an MME 
programme and the same school-related mental tasks which are performed simultaneously during exercises for the same amount of time as the intervention group is training them.

\section{Data collection}

The students of all groups receive anonymised numbers and take part in the same preintervention and postintervention tests. The test design consists of the attention tests Kasel-Concentration-Task (KKA) for Children Aged 3-8 Years (for first-grade and second-grade students); test duration: 6-7 min (KKA) ${ }^{57}$ and d2- $\mathrm{R}^{58}$ (for thirdgrade and fourth-grade students), of a motor performance test battery, the German Motor Performance Test 6-18 (Deutscher Motorik-Test; DMT 6-18), ${ }^{59}$ and the TDS Match 4 Point test (Werthner Sport Consulting AG, Linz, Austria).$^{60}$ A questionnaire to gain supplemental information about leisure time activities will be included for evaluating confounding external variables.

\section{Cognitive tests}

The Kasel-Concentration-Task for Children Aged 3-8 Years; test duration: 6-7 min (KKA) evaluates short-time selective attention and concentration performance of children aged 3-8 years. Every participant receives a test sheet consisting of nine lines and a selection of six target symbols (hand, bell, clock, front side and back side of an envelope, book and bomb). There are 25 different symbols per line. Over a given time span of 10 s per test line (90 s overall), children must cross out one predefined target symbol (eg, the hand symbol). Reference data are available ( $t$ value and percentile values; $n=5.314) .{ }^{61}$ The test is objective, and high validity and reliability have been demonstrated in the age group of 6-8 years (internal consistency $(\alpha=0.92$ to 0.98$)$, parallel test reliability (envelope backside/bell: $\alpha=0.95$ ) and retest reliability $\alpha=0.88$ to 0.91$).{ }^{61}$ The KKA is used to assess the first-grade and second-grade students who will be tested in a group setting of four to six students by a psychologist. Dependent variables are the number of correct crossed-out symbols, the number of errors (errors of omission and commission) and percentage of errors made within all items processed.

The $d 2-R$ test ${ }^{58}$ is suitable for participants aged 9-60 years. The test sheet consists of 14 test lines with 47 characters in each line. Participants are required to scan each test line and cross out all occurrences of the letter ' $d$ ' with two dashes while ignoring other characters (20s per line; $4 \mathrm{~min}$ and $40 \mathrm{~s}$ over all). Reliability depends on the tested age group and ranges between $\alpha=0.89$ and $0.95 .{ }^{62}$ Reference data are available $(\mathrm{n}=4.000)$, and validity is partially high. ${ }^{63}$ The d2-R test is used for all third-grade and fourthgrade students in a group setting - a class is passing the test simultaneously overviewed by their teacher and the psychologist. Dependent variables in the d2-R test are the total number of items processed, total number of errors (errors of omission and errors of commission), percentage of errors made in relation to processed items and a total performance value of attention/concentration ability.

In pilot experiments, the two cognitive tests were pretested on an external group of children (aged 6-9 years) to gain experience in administering the test and to get a first impression if the selected tests are appropriate. The d2-R test was a challenge for the children, but they had no problems understanding and fulfilling the task. However, the KKA (target symbol: backside of a letter) turned out to be too easy for the children (aged 6-8 years) with many achieving hit ratios of $100 \%$. We concluded that the given timeline of $10 \mathrm{~s}$ per test line was too long. Thus, the young test takers finished early and were even waiting for the instruction to continue with next test lines. Hence, in our study, we also apply a modified KKA test with the 'bell' as target symbol and with a limited time span of $45 \mathrm{~s}$ overall. The reduced amount of time of $5 \mathrm{~s}$ per line created more time pressure and lower hit ratio results and therefore offered the possibility of improvement for retesting. Hence, all first-grade and secondgrade students will perform the original KKA modus $(90 \mathrm{~s}$ targeting the 'backside of the letter' symbol) and also the modified version with the limited time of $45 \mathrm{~s}$ targeting the 'bell' symbol.

\section{Physical fitness assessment battery}

Motor performance is assessed by the German Motor Performance Test 6-18 (DMT 6-18) ${ }^{59}$ which offers ageand gender-related Z-parameters of cardiovascular ability (6min endurance run), sprint speed (20 m sprint), strength (sit-up, push-up, standing long jump), flexibility (stand and reach), agility/coordination (jumping sideways), balance (backwards balancing) and overall performance. Test-retest reliability is high $(\alpha=0.82)$, and test results are objective and demonstrated a good validity. ${ }^{64}$

The $6 \mathrm{~min}$ run is used as a measure for aerobic endurance. The children need to run as many rounds (distance of $54 \mathrm{~m}$ ) as possible. For the first two rounds, a sport coach runs in front of the group in moderate speed-children are not allowed to overtake. After the first two rounds, the sport coach drops out and children can choose their own speed. When they get tired, they are allowed to walk but cannot stop. The sport coach watches the group, crosses out the rounds each child passes and, in the end, sums up the running distance for each participant. The dependent variable is the distance one can run in metres (number of rounds times $54 \mathrm{~m}$ plus rest distance).

The $20 \mathrm{~m}$ sprint is measured by an electronic device from Microgate (Witty System; Microgate Srl, Bolzano, Italy). Participants start half a metre behind the first measuring device and sprint as fast as possible to the end of the gym hall. After $20 \mathrm{~m}$, a second device measures the time taken for $20 \mathrm{~m}$. The faster time out of two sprints is used as the dependent variable.

Strength is measured in three different categories: Push-ups are used to assess upper body strength. Students start in resting position and are laying on a mat face down, both hands placed at their back. The exercise starts 
with the placement of the hands under the shoulders, followed by a push up in plank position (without bending the knees), then touching one hand on top of the second hand, again placing both hands under the shoulders and returning to resting position under control. Each push-up is finished when both hands touch the back again. A trainer shows the correct execution, and students perform at least two correct trials before performing the test. The test starts with a countdown (3-2-1 start) and lasts for $40 \mathrm{~s}$. The amount of correct repetitions is used as dependent variable.

Sit-ups serve as a measure of core strength. The trainers show the correct execution of the sit-up: resting position on the mat, both hands beside the head (thumbs are placed under the ear, fingers above the ear), legs are bent in a $90^{\circ}$ angle and one person is holding on to the legs so that they cannot lift from the mat. Starting in resting position, children must lift up and touch their knees with their elbows. The repetition is finished when the whole back (shoulder blades) touch the mat again. Children must do at least two correct repetitions. The test starts with the children in resting position and a countdown (3-2-1 start). The trainer counts the number of correct repetitions over a time span of $40 \mathrm{~s}$.

The standing long jump task measures leg strength. The trainer shows how to execute the jump correctly and tells the children to jump as far as possible using both feet. The better (wider) jump out of two is used as dependent variable.

Flexibility is measured with the stand-and-reach test; children stand on a gymnastic bank and bend forward over an upright plank with measurements. The distance the fingertips reach above $(-\mathrm{cm})$ or past the toes $(+\mathrm{cm})$ is used as dependent variable. The better reach out of two tests is used.

Jumping sideways with both feet is a test that is used to determine coordination under time pressure. The aim is to jump sideways as quickly as possible for $15 \mathrm{~s}$ (best of two trials with a resting period of at least $1 \mathrm{~min}$ ). The jumps must be performed on a squared mat $(100 \times 50 \mathrm{~cm})$ with a wooden beam ( $2 \mathrm{~cm}$ high and $2 \mathrm{~cm}$ wide) in the middle. The relevant parameter for this test is the average number of jumps performed in the two test rounds.

The balancing test assesses coordination under precision constraint: participants are instructed to balance backwards on a $6 \mathrm{~cm}, 4.5 \mathrm{~cm}$ and $3 \mathrm{~cm}$ wide and $3 \mathrm{~m}$ long beam without touching the ground. The children have two trials per beam with the number of steps balanced on each beam added (maximum of 8 steps per trial, maximum score for the complete test is 48 steps).

\section{TDS Match 4 Point}

The TDS Match 4 Point test (Werthner Sport Consulting AG, Linz, Austria) ${ }^{60}$ is used to assess the transfer from optical stimulus to complex motor reaction abilities. The test consists of 24 different patterns displays (1-4 black points shown in four different squares on a monitor; the squares equal pressure plates for the left and right hand and left and right foot). The task is to transfer the shown pattern to the plates which are placed on a table (hands) and on the floor (feet) in front of the subjects. The constellation of shown points must be triggered simultaneously, otherwise the movement has to be repeated. The test is explained in detail and students observe a test trial during which questions may be raised. Then each child completes two test series (one trial and one test) with a minimum of 3 min relaxing time in-between. The reaction times between each stimulus and execution are added up for the test result (sum of reaction times).

\section{Questionnaire}

A questionnaire for evaluating confounding external variables (eg, regular attendance in sport, dance and music classes during leisure time; amount of time doing sports with families and friends, watching TV or playing digital games and reading books) will be included.

\section{Pretest and post-test testing procedures}

Physical assessment tests will be conducted in the gym halls of the schools. Briefed sport coaches oversee the same test station during pre- and post-testing in both schools (no change in taking measurements). Classes are divided into groups of three to maximum five children who pass five test stations in a circle rundown: first station: TDS reaction test; second station: side-jumps, standing long jump, sprint and flexibility; third station: balancing backwards; fourth station: sit-up and push-up; fifth station: 6 min endurance run. The order of the test stations will be the same for pretesting and post-testing. Per test station, each group has a time of $20 \mathrm{~min}$ to pass the tests. Thus, all physical tests are performed within 11/2-2 hours per class (maximum of 24 students).

The d2-R test will take place in class rooms. For the KKA, groups of up to six students will be taken out of class and will perform the test in a quiet seminar room situated in the school building. All cognitive tests are observed by a psychologist.

The questionnaire for evaluating confounding external variables will be conducted after motor and cognitive tests have been completed. Each child will be interviewed individually by a trainer.

\section{DATA ANALYSIS}

Dependent variables of this data collection are: (1) number of crossed out symbols, number of errors (number of ambiguity and mix-up errors), overall performance (KKA and d2-R); (2) running distance (metres, 6 min run), sprint time (seconds, $20 \mathrm{~m}$ sprint), number of repetitions (sit-ups, push-ups, jumping sideways), jumping distance ( $\mathrm{cm}$, long jump), reaching distance ( $\mathrm{cm}$, stand and reach) and number of steps (balance); (3) reaction time (seconds, TDS Match 4 Point test). The test group is the main independent variable (levels: intervention group $\mathrm{A}$, and the two control groups B1 and B2). The children's demographic data (age, male/ female, body height) and confounding external variables 


\section{Data Analysis}

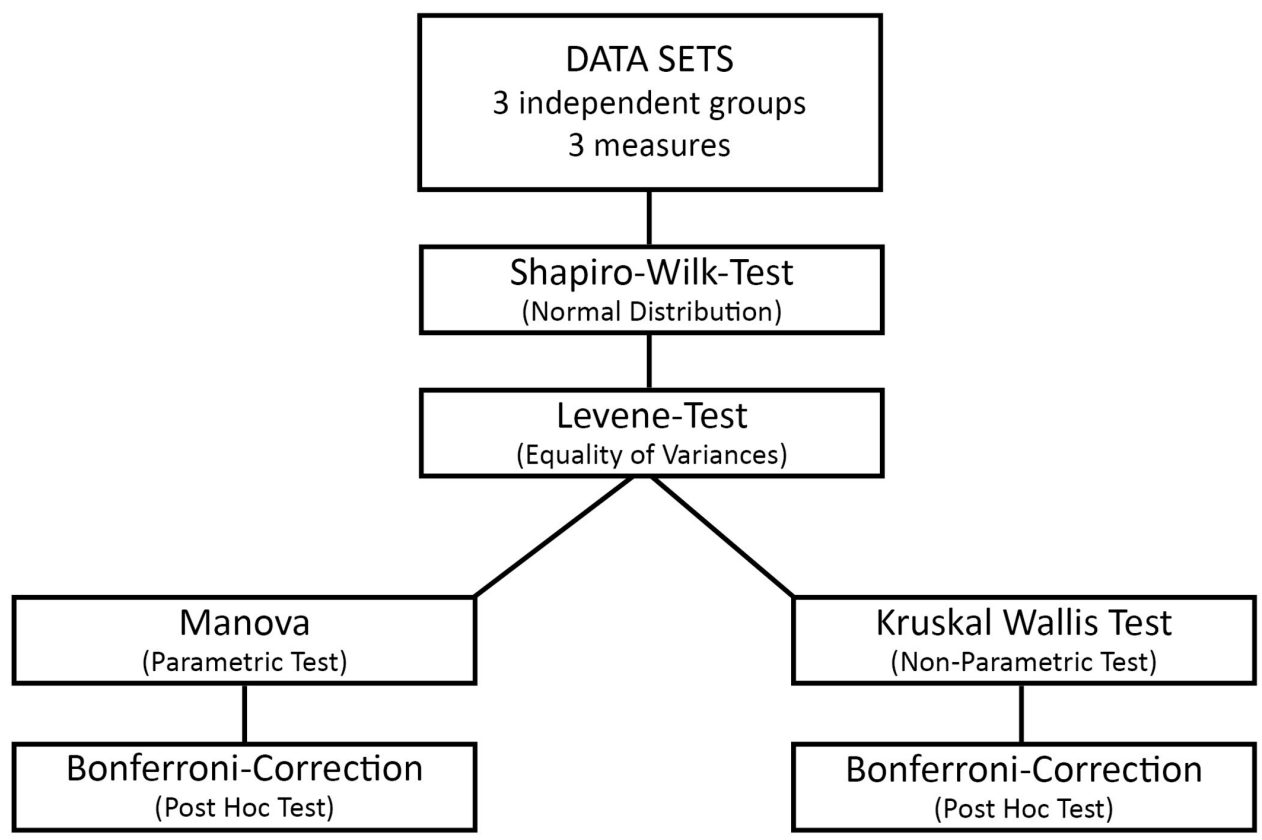

Figure 1 Methods of data analysis. MANOVA, multivariate analysis of variance.

represent additional independent variables or potential covariates. All data are collected in Excel files, transferred to SPSS data files and analysed using SPSS Statistic V.22.0. Descriptive statistics (figure 1) are performed on motor performance data plus attention and reaction test data of all three groups (A, B1 and B2; age; male/female).

Shapiro-Wilk test and graphs (histograms and Q-Qplots) will be used to test the assumption of normal distribution, and the Levene test will be used to evaluate homogeneity of variances in the three different trainings groups. If datasets are normally distributed and meet the assumption of variance homogeneity, a multivariate analysis of variance will be conducted to assess statistical differences between groups and partial eta square $\left(\eta^{2}\right)$ will be calculated as an estimate of effect size. Bonferroni-corrected post hoc comparisons will be used to determine differences among the groups. Effect sizes are calculated through Cohen's $\mathrm{f}$ with values of 0.10 interpreted as small, 0.25 as medium and 0.40 as large effects. Should the dependent variables exhibit non-normal distributions, the non-parametric Kruskal-Wallis test will be performed. For post hoc testing a Bonferroni correction will be applied and Cohen's $\mathrm{r}$ calculated to characterise the effect sizes $(0.10$ small effect, 0.30 medium effect and 0.50 strong effect). For all analyses, the significance level will be set at $\mathrm{p}<0.05$.

\section{Discussion of the main limitations of the current study design}

Probably, the most important limitations of the current study design are (1) the short duration (9 weeks) and low frequency (only one 50 min lesson per week) of the intervention; (2) the decision to assign school A as intervention group and school B for control groups (B1 and B2); thus, it cannot be excluded that differences between the schools might influence the outcome of the study; (3) unequal sample sizes in the groups. Some of the reasons for adopting the current study design are discussed in the following paragraphs.

Longer training periods and frequencies are more likely to result in higher training effects, however, several external boundary conditions limit the intervention period and frequency. One main limiting factor is Austrian school holidays which last from 1 to 9 weeks and appear regularly throughout the year. Choosing the period from school start (September) to the beginning of Christmas holidays (December) offered the longest period available for testing and training interventions (including only 1 week's interruption of autumn holidays). A different/longer intervention period would have implicated many further confounders, for example, sport activities during holidays, seasonal activity school projects (skiing and swimming courses), limited funding availability for trainers, potential declining interest or motivation in the involved teachers and organisers. The chosen period seemed to offer the best compromise for researchers and school authorities. Furthermore, school boards insisted on implementing intervention trainings during regular physical education classes, not as extracurricular activities. They permitted to use one lesson per week for study interventions, while the rest of the physical education curriculum must be taught by the regular teachers.

The decision to assign school $\mathrm{A}$ as intervention group and school B for the control groups (B1 and B2) also resulted from discussions during school board meetings. One concern was 'cross-talk' effects (children of the intervention group showing friends in the control groups some of the intervention exercises). Another concern brought 
forward by the headmasters was to avoid competitiveness between teachers and classes. They asked for one training programme within their school and both school boards concurred with this decision which resulted in inhomogeneous group sizes. Nevertheless, the sample size in all groups will be large enough to statistically detect effects even if their effect sizes are small.

\section{Patient and public involvement}

No patients are involved in this current study. Two public schools with 500 pupils take part in testing and training interventions and 40 teachers support the realisation of planed study steps. School board meetings are used to discuss research questions and to develop a study design that meets school regulations and pupils' needs-the researchers use adequate and established methods and will implement measures as regular school curriculum lessons. Constant communication between school boards, researchers and trainers will assure further adaptive processes. The outcome of this study will be presented in school board meetings. Headmasters and teachers will receive a report of study results and will forward it to interested parents and others involved.

\section{ETHICS AND DISSEMINATION}

The school boards, headmasters, teachers and parents of both participating schools have been informed of the study procedures and have consented to performing the study. Participation is voluntary, and children or their parents can decide to drop out at any time.

The findings of the study will be submitted in 2018 to international journals and presented at national and international conferences. The schools will be informed of key findings and will receive a summary report.

\section{TIMELINES}

The collection of data started with pretesting at the end of September 2017. The intervention period includes October-December 2017 (9-week intervention plus 1 week of school holidays). The postintervention testing will start in December 2017 directly after the intervention phase and retention testing will take place in March 2018 to investigate in effects three months after the intervention phase. Data analysis is planned for January-April 2018. The main outcomes will be presented to the schools before their summer vacation time.

Acknowledgements The authors acknowledge the support of all involved sport coaches (Andrea Danklmayer, Daniela Falch, Stefanie Knoll, Melanie Baumgartner, Elisabeth Huber, Carmen Mitterer and Sigrid Foidl) as well as the help and input of psychologist Ulrike Schuler. We thank all members of the involved School Boards, all teachers and pupils for their contribution in taking part in this study and Sportunion Tirol for funding training interventions. We also thank PH Stams (Joachim Baumann and Tanja Praxmarer) for auditing data analyses.

Contributors AS is the project manager, developed the initial study protocol, statistical treatment and training intervention programmes, and wrote the first draft of the manuscript. MK and PF contributed to developing the study protocol, served as supervisors and critically reviewed and revised the manuscript. All authors agreed with the final version of the manuscript.

Funding This work was supported by Sportunion Tirol (A-6020 Innsbruck, Rennweg 8; www.sportunion-tirol.at), a non-profit head organisation of sport clubs in Tirol.

Competing interests AS developed the suggested Kort. $X$ training intervention programme and offers educational programmes for sport coaches and teachers (www.kortx.info). Furthermore, AS is employed at Sportunion Tirol, the funding organisation (non-profit organisation).

Patient consent Parental/guardian consent obtained.

Ethics approval All procedures have been approved by the Board for Ethical Questions in Science of the University of Innsbruck (approval number 36_2017).

Provenance and peer review Not commissioned; externally peer reviewed.

Open Access This is an Open Access article distributed in accordance with the Creative Commons Attribution Non Commercial (CC BY-NC 4.0) license, which permits others to distribute, remix, adapt, build upon this work non-commercially, and license their derivative works on different terms, provided the original work is properly cited and the use is non-commercial. See: http://creativecommons.org/ licenses/by-nc/4.0/

(c) Article author(s) (or their employer(s) unless otherwise stated in the text of the article) 2018. All rights reserved. No commercial use is permitted unless otherwise expressly granted.

\section{REFERENCES}

1. Hillman $\mathrm{CH}$, Erickson $\mathrm{KI}$, Kramer AF. Be smart, exercise your heart: exercise effects on brain and cognition. Nat Rev Neurosci 2008;9:58-65.

2. Sibley BA, Etnier JL. The relationship between physical activity and cognition in children: a meta-analysis. Pediatr Exerc Sci 2003;15:243-56.

3. Chaddock-Heyman L, Hillman $\mathrm{CH}$, Cohen NJ, et al. III. The importance of physical activity and aerobic fitness for cognitive control and memory in children. Monogr Soc Res Child Dev 2014;79:25-50.

4. Davis CL, Cooper S. Fitness, fatness, cognition, behavior, and academic achievement among overweight children: do crosssectional associations correspond to exercise trial outcomes? Prev Med 2011;52 Suppl 1(Suppl 1):S65-S69.

5. Sardinha LB, Marques A, Martins S, et al. Fitness, fatness, and academic performance in seventh-grade elementary school students. BMC Pediatr 2014;14:176.

6. Marques A, Santos DA, Hillman $\mathrm{CH}$, et al. How does academic achievement relate to cardiorespiratory fitness, self-reported physical activity and objectively reported physical activity: a systematic review in children and adolescents aged 6-18 years. Br J Sports Med 2017: bjsports-2016-097361.

7. Lopes L, Santos R, Pereira B, et al. Associations between gross motor coordination and academic achievement in elementary school children. Hum Mov Sci 2013;32:9-20.

8. Esteban-Cornejo I, Tejero-Gonzalez CM, Sallis JF, et al. Physical activity and cognition in adolescents: a systematic review. J Sci Med Sport 2015;18:534-9.

9. Hillman $\mathrm{CH}$, Biggan JR. A review of childhood physical activity, brain, and cognition: perspectives on the future. Pediatr Exerc Sci 2017;29:170-6.

10. Howie EK, Pate RR. Physical activity and academic achievement in children: a historical perspective. J Sport Health Sci 2012;1:160-9.

11. Donnelly JE, Hillman $\mathrm{CH}$, Castelli D, et al. Physical activity, fitness, cognitive function, and academic achievement in children: a systematic review. Med Sci Sports Exerc 2016;48:1197-222.

12. Pontifex MB, Scudder MR, Drollette ES, et al. Fit and vigilant: the relationship between poorer aerobic fitness and failures in sustained attention during preadolescence. Neuropsychology 2012;26:407-13.

13. Etnier JL, Nowell PM, Landers DM, et al. A meta-regression to examine the relationship between aerobic fitness and cognitive performance. Brain Res Rev 2006;52:119-30.

14. Hillman $\mathrm{CH}$, Schott N. Der Zusammenhang von Fitness, kognitiver Leistungsfähigkeit und Gehirnzustand im Schulkindalter. Zeitschrift für Sportpsychologie 2013;20:33-41.

15. Buck SM, Hillman CH, Castelli DM. The relation of aerobic fitness to stroop task performance in preadolescent children. Med Sci Sports Exerc 2008;40:166-72. 
16. Pontifex MB, Raine LB, Johnson CR, et al. Cardiorespiratory fitness and the flexible modulation of cognitive control in preadolescent children. J Cogn Neurosci 2011;23:1332-45.

17. Scudder MR, Lambourne K, Drollette ES, et al. Aerobic capacity and cognitive control in elementary school-age children. Med Sci Sports Exerc 2014;46:1025-35.

18. Maher C, Lewis L, Katzmarzyk PT, et al. The associations between physical activity, sedentary behaviour and academic performance. J Sci Med Sport 2016;19:1004-9.

19. Drollette ES, Shishido T, Pontifex MB, et al. Maintenance of cognitive control during and after walking in preadolescent children. Med Sci Sports Exerc 2012;44:2017-24

20. Hillman $\mathrm{CH}$, Pontifex MB, Raine LB, et al. The effect of acute treadmill walking on cognitive control and academic achievement in preadolescent children. Neuroscience 2009;159:1044-54.

21. de Greeff JW, Bosker RJ, Oosterlaan J, et al. Effects of physical activity on executive functions, attention and academic performance in preadolescent children: a meta-analysis. J Sci Med Sport 2018;21.

22. Hillman $\mathrm{CH}$, Pontifex MB, Castelli DM, et al. Effects of the FITKids randomized controlled trial on executive control and brain function. Pediatrics 2014;134:e1063-71.

23. Davis CL, Tomporowski PD, McDowell JE, et al. Exercise improves executive function and achievement and alters brain activation in overweight children: a randomized, controlled trial. Health Psychol 2011;30:91-8.

24. Tarp J, Domazet SL, Froberg K, et al. Effectiveness of a schoolbased physical activity intervention on cognitive performance in Danish adolescents: LCoMotion-Learning, cognition and motion - a cluster randomized controlled trial. PLoS One 2016;11:e0158087.

25. Diamond A, Ling DS. Conclusions about interventions, programs, and approaches for improving executive functions that appear justified and those that, despite much hype, do not. Dev Cogn Neurosci 2016;18:34-48.

26. Tsai CL, Chen FC, Pan CY, et al. Impact of acute aerobic exercise and cardiorespiratory fitness on visuospatial attention performance and serum BDNF levels. Psychoneuroendocrinology 2014;41:121-31.

27. Chaddock L, Erickson KI, Prakash RS, et al. A neuroimaging investigation of the association between aerobic fitness, hippocampal volume, and memory performance in preadolescent children. Brain Res 2010;1358:172-83.

28. Chaddock L, Hillman $\mathrm{CH}$, Buck SM, et al. Aerobic fitness and executive control of relational memory in preadolescent children. Med Sci Sports Exerc 2011;43:344-9.

29. Scudder MR, Federmeier KD, Raine LB, et al. The association between aerobic fitness and language processing in children: implications for academic achievement. Brain Cogn 2014;87:140-52.

30. Ishihara T, Sugasawa S, Matsuda Y, et al. Improved executive functions in 6-12-year-old children following cognitively engaging tennis lessons. J Sports Sci 2017;35:2014-20.

31. Pesce C, Crova C, Cereatti L, et al. Physical activity and mental performance in preadolescents: Effects of acute exercise on freerecall memory. Ment Health Phys Act 2009;2:16-22.

32. Schmidt M, Jäger K, Egger F, et al. Cognitively engaging chronic physical activity, but not aerobic exercise, affects executive functions in primary school children: a group-randomized controlled trial. J Sport Exerc Psychol 2015;37:575-91.

33. van der Niet AG, Smith J, Oosterlaan J, et al. Effects of a cognitively demanding aerobic intervention during recess on children's physical fitness and executive functioning. Pediatr Exerc Sci 2016;28:64-70.

34. Crova C, Struzzolino I, Marchetti R, et al. Cognitively challenging physical activity benefits executive function in overweight children J Sports Sci 2014;32:201-11.

35. Oberer N, Gashaj V, Roebers CM. Motor skills in kindergarten: internal structure, cognitive correlates and relationships to background variables. Hum Mov Sci 2017;52:170-80.

36. Roebers CM, Röthlisberger M, Neuenschwander R, et al. The relation between cognitive and motor performance and their relevance for children's transition to school: a latent variable approach. Hum Mov Sci 2014;33:284-97.

37. Geertsen SS, Thomas R, Larsen MN, et al. Motor skills and exercise capacity are associated with objective measures of cognitive functions and academic performance in preadolescent children. PLoS One 2016;11:e0161960.

38. Budde H, Voelcker-Rehage C, Pietrabyk-Kendziorra S, et al. Acute coordinative exercise improves attentional performance in adolescents. Neurosci Lett 2008;441:219-23.
39. Stein M, Auerswald M, Ebersbach M. Relationships between motor and executive functions and the effect of an acute coordinative intervention on executive functions in kindergartners. Front Psychol 2017:8:859.

40. Liu J-H, Alderman BL, Song T-F, et al. A randomized controlled trial of coordination exercise on cognitive function in obese adolescents. Psychol Sport Exerc 2018;34:29-38.

41. Jansen $P$, Lange $L$, Heil $M$. The influence of juggling on mental rotation performance in children. Biomedical Human Kinetics 2011:3:149.

42. Lehmann J, Jansen P. The influence of juggling on mental rotation performance in children with spina bifida. Brain Cogn 2012;80:223-9.

43. Chang YK, Tsai YJ, Chen TT, et al. The impacts of coordinative exercise on executive function in kindergarten children: an ERP study. Exp Brain Res 2013;225:187-96.

44. Gallotta MC, Emerenziani GP, lazzoni S, et al. Impacts of coordinative training on normal weight and overweight/obese children's attentional performance. Front Hum Neurosci 2015;9:577.

45. Tomporowski PD, McCullick B, Pendleton DM, et al. Exercise and children's cognition: The role of exercise characteristics and a place for metacognition. J Sport Health Sci 2015:4:47-55.

46. Falbo S, Condello G, Capranica L, et al. Effects of physical-cognitive dual task training on executive function and gait performance in older adults: a randomized controlled trial. Biomed Res Int 2016;2016:1-12

47. Elhinidi El, Ismaeel MM, El-Saeed TM. Effect of dual-task training on postural stability in children with infantile hemiparesis. $J$ Phys Ther Sci 2016;28:875-80.

48. Wu T, Liu J, Hallett M, et al. Cerebellum and integration of neural networks in dual-task processing. Neuroimage 2013;65:466-75

49. Schlaug G, Forgeard M, Zhu L, et al. Training-induced neuroplasticity in young children. Ann N Y Acad Sci 2009;1169:205-8.

50. Magallón S, Narbona J, Crespo-Eguílaz N. Acquisition of motor and cognitive skills through repetition in typically developing children. PLoS One 2016;11:e0158684.

51. van Raalten TR, Ramsey NF, Duyn J, et al. Practice induces functionspecific changes in brain activity. PLoS One 2008;3:e3270.

52. Willner CJ, Gatzke-Kopp LM, Bierman KL, et al. Relevance of a neurophysiological marker of attention allocation for children's learning-related behaviors and academic performance. Dev Psychol 2015;51:1148-62.

53. Stevens $C$, Bavelier $D$. The role of selective attention on academic foundations: a cognitive neuroscience perspective. Dev Cogn Neurosci 2012;2(Suppl 1):S30-48.

54. Lan X, Legare $\mathrm{CH}$, Ponitz CC, et al. Investigating the links between the subcomponents of executive function and academic achievement: a cross-cultural analysis of Chinese and American preschoolers. J Exp Child Psychol 2011;108:677-92.

55. Rusch T, Korn CW, Gläscher J. A two-way street between attention and learning. Neuron 2017:93:256-8.

56. Weineck J. Optimales Training: Leistungsphysiologische Trainingslehre unter besonderer Berücksichtigung des Kinder- und Jugendtrainings. 16th edn. Balingen: Spitta, 2010.

57. Krampen G. Kaseler-Konzentrations-Aufgabe für 3- bis 8-Jährige. Manual. Göttingen, Bern, Wien: Hogrefe, 2007.

58. Brickenkamp R, Schmidth-Atzert L, Liepmann D. Test d2 - Revision: Aufmerksamkeits- und Konzentrationstest. Göttingen, Bern, Wien: Hogrefe, 2010.

59. Bös K. Deutscher Motorik-Test 6-18: (DMT 6-18) manual und internetbasierte Auswertungssoftware. 2nd edn. Hamburg: Feldhaus Edition Czwalina, 2016.

60. Voss G, Witt M, Werthner R. Herausforderung Schnelligkeitstraining. Aachen: Meyer \& Meyer, 2007.

61. In: Kipman U, Fritz A, eds. Psychologische Diagnostik von Aufmerksamkeits- und Konzentrationsfähigkeit im Kindergartenund Schulalter. Salzburg: Österreichisches Zentrum für Begabtenförderung und Begabtenforschung (ÖZBF), 2014.

62. Brickenkamp R, Schmidth-Atzert L, Liepmann D. Test d2 - Revision: Aufmerksamkeits- und Konzentrationstest. Göttingen and Bern and Wien: Hogrefe, 2010.

63. Daseking M, Putz D. TBS-TK Rezension. Psychologische Rundschau 2015;66:265-7.

64. Oberger J. Sportmotorische Tests im Kindes- und Jugendalter: Normwertbildung - Auswertungsstrategien Interpretationsmöglichkeiten; Überprüfung anhand der Daten des Motorik-Moduls (MoMo). Karlsruher Sportwissenschaftliche Beiträge;6. Karlsruhe: KIT Scientific Publishing, 2015. 